\title{
TERAPIA OCUPACIONAL EN EL MANEJO INTEGRAL DEL PACIENTE CON ENFERMEDAD REUMATICA
}

\section{Síntesis de Trabajo de Grado Modalidad Pasantía}

\author{
Autoras \\ Astrith Morales Barrera \\ Obeida Esmeralda Preciado Jiménez \\ Adriana Velásquez Navarro \\ Terapeutas Ocupacionales \\ Universidad Nacional de Colombia, 1997. \\ Directora \\ Nohora Stella Díaz Cubillos \\ Terapeuta Ocupácional, M.A.S \\ Docente Universidad Nacional de Colombia
}

Este trabajo de Grado fue elaborado y sustentado como requisito para optar al título de. Terapéutas Ocupacionales, siendo a su vez distinguido con Mención Meritoria, bajo la Resolución 038 de la Facultad de Medicina, Universidad Nacional de Colombia.

Terapia Ocupacional se ha interesado por el abordaje de aquellas enfermedades que limitan el Desempeño Ocupacional del individuo en cualquier etapa del ciclo de la vida, dentro de las cuales se encuentran Las Enfermedades Reumáticas, que afectan los componentes físico, afectivo y social, llevando el desempeño a un nivel disfuncional.

Por tal razón el Terapétúa Ocupacional gụía sus acciones hacia el desarrollo de una intervención integral, ofreciendo alternativas de tratamiento que 
involucran el medio ambiente que rodea al individuo, lo que permite establecer cambios $y / 0$ modificaciones, tanto a nivel de hábitos y rutinas diarias, como en el mejoramiento de las condiciones fisicas del ambiente para llegar a una realización independiente y eficaz de las actividades de Autocuidado, Tiempo Libre y Trabajo particulares.

De acuerdo con las Disposiciones Generales Reglamentarias de Sistema General de Seguridad Social, la Terapia Ocupacional como profesión en el área de la Salud, ha considerado generar nuevas estrategias para la prestación de servicios, al identificar necesidades especificas que promueven la atención integral y especializada del paciente y de esta forma, participar ampliamente no solo en el cumplimiento de la legislación Colombiana, sino además, contribuir al fortalecimiento del ejercicio profesional.

Para la realización de éste trabajo, los objetivos fueron orientados hacia la implementación de un Programa de Atención para el Manejo Integral del Paciente con Enfermedad Reumática, teniendo en cuenta los niveles de prevención y rehabilitación, en donde cada uno de los componentes del Desempeño Ocupacional fueran abordados, para permitirle al individuo alcanzar su máximo nivel de autonomía, funcionalidad y bienestar, durante la realización de las diversas actividades que conforman su quehacer diario. Paralelo a esto, se busco fortalecer la fundamentación teórica de la práxis profesional del Terapéuta Ocupacional en la intervención de la discapacidad física, especialmente dentro del área de la Reumatología, para llegar así a la consolidación de Planes de Tratamiento integrales, respondiendo a las necesidades del paciente.

El desarrollo del Programa de Atención Integral fue llevado a cabo durante el Segundo Semestre de 1996, en la Fundación Instituto de Reumatología e 
Inmunología, institución sin ánimo de lucro, reconocida por ofrecer una atención especializada a esta población.

Para la planeación de dicho programa, fue necesario considerar las implicaciones fisicas, emocionales y sociales que causan en el paciente enfermedades como la Artritis Reumatoidea, Lupus Erimatoso Sistémico y Osteoartritis, sustentando teóricamente bajo dos enfoques, Biomecánico y de Rehabilitación, que brindan al Terapéuta Ocupacional propósitos de intervención específicos dentro del plan de tratamiento, de acuerdo a características y necesidades individuales.

Con el fin de obtener un mejor registro de datos, fueron utilizados instrumentos de evaluación, los cuales se aplicaron al inicio y al final del tratamiento a cada paciente, como Evaluación de Amplitud Articular, Valoración Muscular, Actividades Básicas Cotidianas y de la Vida Diaria y Evaluación del Medio Ambiente. Por medio de éste Proceso Evaluativo se determinó el nivel de Atención, es decir, Institucional o Domiciliario. Con el servicio de Atención Domiciliaria se dio al programa el sentido de integralidad en el abordaje al paciente y su medio ambiente y así alcanzar un nivel de Desempeño Ocupacional acorde con las demandas físicas y psicosociales.

Las alternativas de tratamiento propuestas para la intervención de Terapia Ocupacional fueron: Técnicas de Protección Articular, Conservación de Energía y Simplificación del Trabajo; Plan de Actividad Física; Ferulaje y Aditamentos; Visita Domiciliaria; Equipo Asistido y Adaptaciones al Medio Ambiente; Actividad Terapéutica; Orientación Vocacional y Laboral. Se desarrollaron paralelamente Estrategias Educativas, basadas en la realización de Talleres y Conferencias orientados al conocimiento y comprensión del proceso evolutivo de la enfermedad e implicaciones funcionales en el Desempeño Ocupacional. 
La ejecución de este programa permitió establecer una serie de lineamientos que hacen referencia al papel que cumple el Terapéuta Ocupacional en el abordaje de pacientes dentro del área de Reumatología y como éste, puede proponer y emplear diversas alternativas de tratamiento, que le permiten desarrollar habilidades y destrezas para la identificación efectiva de necesidades y problemáticas del paciente. Así, el Terapéuta Ocupacional se convierte en uno de los profesionales capacitados para brindar servicios de calidad e integralidad, cubriendo diferentes aspectos de las entidades clínicas que puedan afectar la funcionalidad del Desempeño Ocupacional del individuo.

Finalmente el ejercicio del Terapéuta Ocupacional durante el desarrollo de tratamientos específicos, promueve su rol profesional hacia el enriquecimiento y fortalecimiento del objeto de estudio de su comunidad científica, mediante la innovación implementación y reformulación de estrategias de intervención planteadas durante los últimos años. 